\title{
STRATEGI PENGEMBANGAN BALAI INSEMINASI BUATAN LEMBANG KABUPATEN BANDUNG BARAT DENGAN PENDEKATAN BUSINESS MODEL CANVAS
}

\author{
DEVELOPMENT STRATEGY OF BALAI INSEMINASI BUATAN LEMBANG WEST BANDUNG REGENCY \\ WITH BUSINESS MODEL CANVAS APPROACH
}

\author{
Dwipanca Prabuwisudawan*)1, Amzul Rifin ${ }^{* *}$, dan Setiadi Djohar ${ }^{* * *}$ \\ ${ }^{*}$ Sekolah Bisnis, Institut Pertanian Bogor \\ Jl. Raya Pajajaran, Bogor 16151 \\ ${ }^{* *}$ Departemen Agribisnis, Fakultas Ekonomi dan Manajemen, Institut Pertanian Bogor \\ Jl. Agatis Kampus IPB Darmaga, Bogor 16880 \\ ${ }^{* * *)}$ Sekolah Tinggi Manajemen PPM \\ J1. Menteng Raya No. 9-19, DKI Jakarta 10340
}

\begin{abstract}
The primary function of Government is to provide the best service to meet community needs in all sectors. One sector that plays an important role in fulfilling the needs of the community are the livestock sectors. Balai Inseminasi Buatan (BIB) Lembang is one of the perpetrators of farm that plays an important role in fulfilling the needs of the community in the livestock sector. This study aims to 1) identify existing business model of BIB Lembang by using business model canvas, 2) create business model that has been enhanced with approach business model canvas 3) making improvement programs from improved business models. The method used is business model canvas approach and SWOT analysis. Based on the results of the study, it is obtained that the nine elements of the business model BIB Lembang are co-creator, value proposition, channels, relations, value stream-returns, key resources, key activities, key partnership, and value stream-outlay and costs, making repair business model based on SWOT analysis on each element, as well as repair program in the form of an internal development organization, distribution channels, information, and communication, as well as financial management based on Badan Layanan Umum (BLU).
\end{abstract}

Keywords: BIB, business model canvas, livestock, development strategy, SWOT

\begin{abstract}
Abstrak: Fungsi utama pemerintah adalah memberikan pelayanan terbaik untuk memenuhi kebutuhan masyarakat di semua sektor. Salah satu sektor yang berperan penting dalam pemenuhan kebutuhan masyarakat adalah sektor peternakan. Balai Inseminasi Buatan (BIB) Lembang merupakan salah satu pelaku usaha peternakan yang memegang peranan penting dalam pemenuhan kebutuhan masyarakat dalam sektor peternakan. Penelitian ini betujuan untuk 1) mengidentifikasi model bisnis BIB Lembang dengan menggunakan business model canvas, 2) membuat model bisnis yang telah disempurnakan dengan pendekatan business model canvas 3) membuat program perbaikan dari model bisnis yang telah disempurnakan. Metode yang digunakan adalah pendekatan business model canvas dan analisis SWOT. Berdasarkan hasil kajian didapatkan sembilan elemen model bisnis BIB Lembang antara lain co-creator, value proposition, channels, relations, value stream-returns, key resources, key activities, key partership, dan value stream-outlay and costs, pembuatan model bisnis perbaikan berdasarkan analisis SWOT pada masing-masing elemen, serta program perbaikan berupa pengembangan internal organisasi, saluran distribusi, informasi, dan komunikasi, serta pengelolaan keuangan berbasis Badan Layanan Umum (BLU).
\end{abstract}

Kata kunci: BIB, business model canvas, peternakan ,strategi pengembangan, SWOT

\footnotetext{
${ }^{1}$ Alamat Korespondensi:

Email: dwipanca.p@gmail.com
} 


\section{PENDAHULUAN}

Pemerintah memiliki fungsi utama dalam memberikan pelayanan terbaik untuk memenuhi kebutuhan masyarakat di semua sektor. Pengembangan manajemen proses bisnis perlu dilakukan untuk mengoptimalkan pelayanan yang diberikan sehingga perlu dilakukan pada sektor pemerintah, menurut Becker et al. (2006) organisasi pemerintahan perlu melakukan evaluasi kembali terhadap proses bisnis seperti melakukan manajemen keuangan dan pelayanan masyarakat. Perbaikan proses bisnis penting dilakukan untuk memberikan gambaran bentuk pemerintahan dalam menciptakan struktur yang tepat untuk meningkatkan kinerja proses bisnis organisasi. Perubahan yang dilakukan oleh organisasi membutuhkan perencanaan yang baik. perencanaan perubahan tersebut hendaknya dilakukan di berbagai bidang organisasi agar perubahan yang dilakukan dapat meningkatkan performa organisasi (Darmawati, 2007). Sektor peternakan merupakan salah satu sektor penting dalam pemenuhan kebutuhan masyarakat dan memiliki potensi besar untuk dikembangkan di Indonesia didasarkan pada kondisi sumberdaya alam yang mendukung dan potensi pasar berupa jumlah penduduk yang besar. Akan tetapi, belum dapat diwujudkan secara optimal di lapangan. Faktor-faktor teknis seperti kurangnya teknologi tepat guna dan ketersediaan bibit unggul seringkali menjadi faktor penghambat dalam pengembangan peternakan.

Pada tahun 2015, produksi daging nasional baru tercapai 67\% (497.700 ton) dari total kebutuhan daging sebesar 744.534 ton dan kekurangan daging dipenuhi melalui import sebesar 33\% (246.834 ton). Pasokan import daging diprediksikan semakin meningkat seiring bertambahnya jumlah penduduk dan meningkatnya konsumsi produk peternakan. Peningkatan import sapi potong dan daging merupakan indikasi peningkatan permintaan daging atau ketidaksanggupan pemenuhan kebutuhan yang harus dipasok oleh produksi sapi potong dalam negeri. Upaya pemenuhan kebutuhan daging hanya dari sapi lokal akan mengakibatkan pengurasan sapi potong lokal (Romjali et al. 2007).

Salah satu upaya untuk meningkatkan produksi dan populasi sapi potong dapat dilakukan dengan bioteknologi peternakan, yaitu pemanfaatan proses biologis melalui rekayasa genetik dan rekayasa proses untuk menghasilkan ternak dan produk peternakan yang berkualitas. Bioteknologi peternakan di Indonesia mencakup beberapa ruang lingkup, salah satu yang dilakukan oleh pemerintah untuk meningkatkan produktivitas sapi potong adalah program inseminasi buatan (IB).

Dalam rangka pengembangan sektor peternakan di Indonesia, maka pemerintah mendirikan Balai Inseminasi Buatan(BIB)Lembang yang berfungsi untuk memenuhi kebutuhan pelaksanaan inseminasi buatan di Indonesia. BIB Lembang bertugas menghasilkan produk, berupa semen beku unggul untuk membuktikan komitmen yang tinggi dalam mendukung program pemerintah. Namun, seiring dengan pelaksanaanya, terdapat beberapa permasalahan yang dihadapi oleh BIB Lembang, yaitu menurunnya tingkat produktitivitas sapi serta informasi penyampaian nilai yang diberikan BIB Lembang terkait pengembangan inseminasi buatan di Indonesia belum merata ke seluruh daerah.

Salah satu upaya pendekatan dalam membuat suatu pengembangan adalah dengan menggunakan model bisnis. Menurut Dudin et al. (2015) model bisnis dapat menggambarkan skenario pengembangan lebih lanjut dan perubahan tingkat daya saing suatu organisasi. Model bisnis mencerminkan pilihan strategis dan implikasi operasional yang membantu perusahaan untuk mengkomunikasikan, menganalisis, menguji dan memvalidasi sebuah hubungan sebab-akibat yang berasal dari pilihan strategi yang dibuat (Shafer et al. 2005).

Penelitian ini bertujuan (1) mengindetifikasi model bisnis yang ada di BIB Lembang saat ini melalui pendekatan business model canvas, (2) membuat model bisnis perbaikan dengan pendekatan business model canvas, (3) membuat strategi pengembangan berupa program perbaikan dari model bisnis yang telah disempurnakan.

Ruang lingkup yang menjadi fokus penelitian ini adalah BIB yang terdapat di Lembang Kabupaten Bandung Barat, Jawa Barat. Penelitian ini berfokus pada penyusunan model bisnis masa depan, perbaikan model bisnis, dan pembuatan program berdasarkan model bisnis yang telah disempurnakan. 


\section{METODE PENELITIAN}

Penelitian ini dilakukan di Balai Inseminasi Buatan (BIB) Lembang-Bandung, yang berlokasi pada Kecamatan Lembang, Kabupaten Bandung Barat. Pemilihan lokasi ini dilakukan secara sengaja (purposive) dengan pertimbangan bahwa BIB Lembang memiliki potensi untuk dapat lebih dikembangkan.

Penelitian ini menggunakan dua jenis data yang terdiri dari data primer dan data sekunder baik yang diperoleh dari internal maupun eksternal organisasi. Data primer diperoleh melalui hasil observasi/pengamatan lapang dan wawancara dengan badan pengelola BIB Lembang. Sedangkan data sekunder diperoleh melalui studi pustaka dari instansi dan kelembagaan pemerintah yang terkait. Instrumen pengumpulan data sekunder melalui literatur yang mendukung dan studi kepustakaan, serta data-data yang diperoleh melalui publikasi yang diterbitkan dan pencarian melalui situs-situs internet.

Teknik pengumpulan data yang digunakan dalam penelitian ini adalah wawancara, observasi, dan studi dokumentasi. Pengumpulan data ini digunakan dengan tujuan untuk memperoleh data dan informasi yang diperlukan untuk menjawab pertanyaan dalam rumusan masalah dalam penelitian.

Metode yang digunakan dalam penelitian ini adalah metode deskriptif dengan jenis penelitian studi kasus. Metode penelitian deskriptif digunakan untuk memperoleh gambaran informasi, penjelasan, dan kondisi yang berkaitan dengan obyek penelitian secara akurat dan sistematis. Penelitian dengan metode studi kasus menghendaki suatu kajian yang rinci, mendalam dan menyeluruh atas objek tertentu yang biasanya relatif kecil dalam kurun waktu tertentu, termasuk lingkungannya (Umar, 2010).

Penelitian dilakukan dengan pendekatan Business Model Canvas (BMC). Pendekatan BMC berpedoman pada wawancara yang dilakukan terhadap responden mengenai sembilan elemen BMC di BIB Lembang. Dari hasil analisis BMC tersebut kemudian dilanjutkan dengan analisis SWOT pada masing-masing elemen BMC untuk dilakukan penyempurnaan, dan kemudian dilakukan perumusan strategi pengembangannya.

Sinfield et al. (2012) mendefinisikan model bisnis adalah segala aspek yang dimiliki oeh suatu organisasi untuk mengembangkan penawaran yang menguntungkan kepada konsumen. BMC berguna untuk memahami keadaan suatu organisasi dan melakukan inovasi model bisnis pada oraganisasi tersebut, namun dalam penerapannya terhadap organisasi sosial perlu penyesuaian agar dapat menangkap model bisnis organisasi sosial sepenuhnya (Qastharin, 2016).

Objek penelitian ini merupakan organisasi non profit, sehingga dilakukan penyesuaian terhadap beberapa blok elemen yang terdapat pada BMC. Penyesuain blok elemen BMC organisasi non profit telah dilakukan oleh Graves(2010) dimana mengubah blok customer segment menjadi co-creator, customer Relationship menjadi Relations, revenue stream menjadi value stream-return, dan cost structure menjadi value stream-outlay and costs. Perubahan yang dilakukan pada empat elemen tersebut, agar model kanvas yang bersifat profitable to customer menjadi bersifat non monetary dan bertujuan pada nilai capaian. Alur ringkasan kerangka penelitian dapat dilihat pada pada Gambar 1.

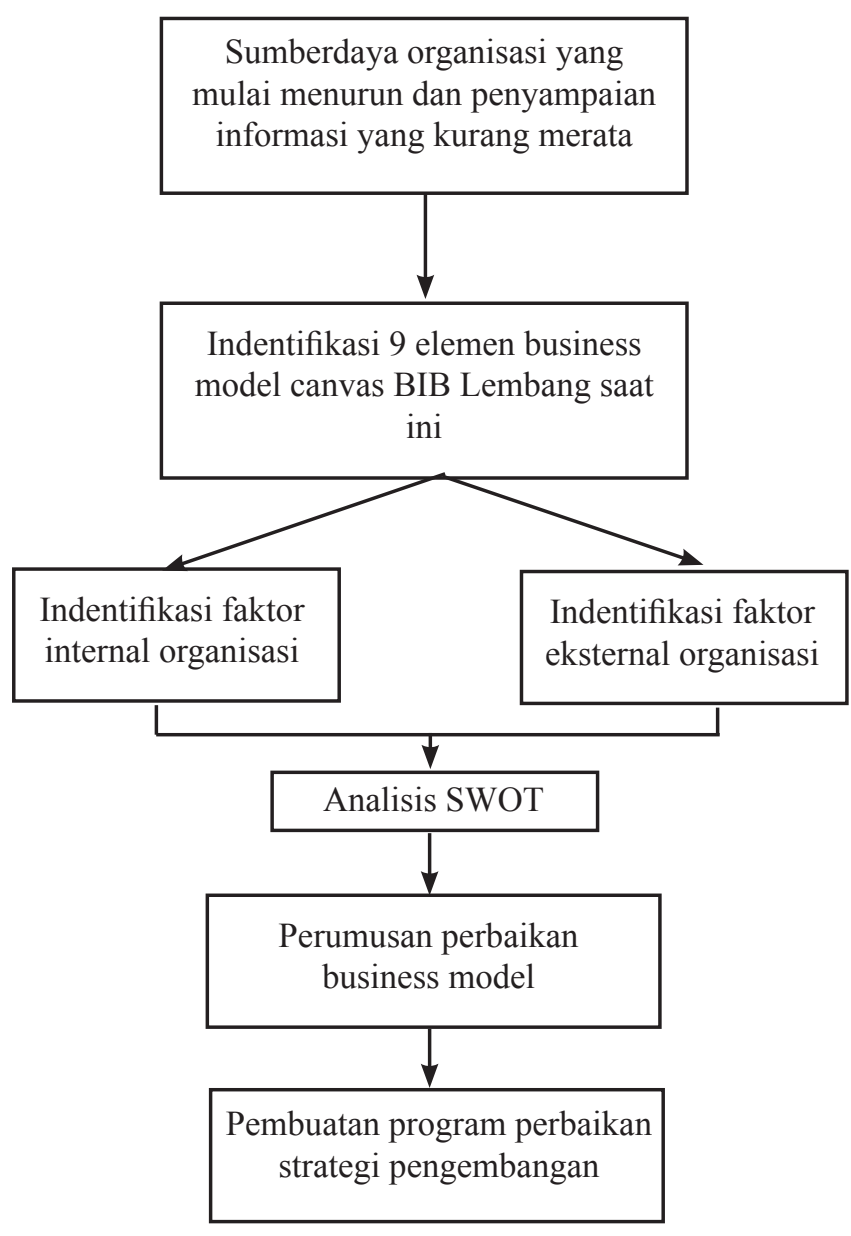

Gambar 1. Kerangka pemikiran penelitian 


\section{HASIL}

\section{Identifikasi Elemen BMC BIB Lembang Saat Ini}

Penelitian ini melibatkan orang-orang yang terkait denganBIBLembang sebagairespondenuntukmemotret keadaan BMC saat ini. Penelitian dilakukan dalam dua tahap, tahap pertama adalah melakukan identifikasi model bisnis yang ada di BIB Lembang dengan melakukan wawancara dengan pihak terkait seperti Kepala Balai, Kepala Sub-Bagian Tata Usaha, Kepala Seksi Pelayanan, serta mitra usaha untuk mengetahui gambaran model bisnis yang ada dengan pendekatan BMC. Awalnya responden dijelaskan mengenai BMC lalu dilakukan wawancara terkait elemen-elemen yang berada di dalamnya. Setelah didapat model bisnis yang ada pada saat ini, tahap selanjutnya adalah dilakukan analisis SWOT terhadap model bisnis yang ada secara bersama-sama. Setelah didapat hasil analisis SWOT dari masin-masing elemen, maka dilakukan analisis secara kualitatif untuk perbaikan model bisnis dari yang ada saat ini.

Dalam penelitian ini, dilakukan penyesuaian terhadap BMC dikarenakan objek penelitian merupakan organisasi non profit. Identifikasi dilakukan pada sembilan blok elemen yang telah disesuaikan adalah sebagai berikut:

\section{Co-Creator}

Co-Creator merupakan penciptaan bersama suatu nilai oleh organisasi dan stakeholder terkait agar memungkinkan melakukan penyesuaian terhadap nilai yang ditawarkan (Prahalad dan Ramaswamy, 2004). BIB Lembang melakukan koordinasi dengan direktorat perbibitan dan produksi ternak dalam melaksanakan kegiatan yang berlangsung. Selain itu BIB Lembang mempunyai co-creator lain yang dapat menikmati nilai yang ditawarkan, antara lain adalah kelompok peternak, baik peternak mitra maupun peternak mandiri atau swasta, serta masyarakat umum.

\section{Value Proposition}

Value proposition disini merupakan nilai atau manfaat yang dapat berupa produk maupun jasa yang diberikan oleh organisasi terhadap stakeholder yang terkait. Sebuah model bisnis yang sukses harus memiliki keunggulan dari value proposition yang dapat dijdikan keunggulan kompetitif untuk meningkatkan hubungan antar elemen yang dimiliki (Morris, 2009). Manfaat utama yang dapat ditawarkan BIB Lembang saat ini berupa penyediaan bibit semen beku unggul, dan value proposition tambahan berupa asistensi dan konsultasi peternakan, serta pemanfaatan aset balai.

\section{Channels}

Channels merupakan saran yang digunakan untuk menyampaikan value proposition terhadap pelanggan. Channels yang dimiliki oleh BIB Lembang saat ini terdiri dari dua jenis, yaitu saluran distribusi langsung dan saluran tidak langsung. Saluran distribusi langsung dilakukan dengan menggunakan media online atau internet, sedangkan saluran distribusi tidak langsung, yaitu BIB Lembang menggunakan bantuan mitra dalam melakukan dsitribusi yang dilakukan. Menurut Apavaloaie (2014) dampak internet memberikan kesempatan baru dalam berinovasi, dimana melalui internet terjadi perubahan dalam bagaimana cara menginformasikan, menghubungi pelanggan, pemasok dan karyawan, dalam pemasaran, promosi dan kegiatan bisnis lainnya.

\section{Relations}

Relations merupakan suatu upaya yang dilakukan organisasi dalam menjaga hubungan dengan stakeholder. Menurut Lasker dan Weiss (2003) Relations merupakan sinergi yang penting untuk diidentifikasi, karena dapat berdampak memengaruhi kesehatan suatu organisasi/ instansi pada siapapun stakeholder yang terlibat dengan interaksinya. Ide baru akan dapat mengembangkan interaksi hubungan yang baik antara organisasi dengan individu organisasi, kemudian akan lebih jauh lagi akan dapat mengembangkan interaksi antara organisasi dengan pelanggannya (Mardiyanto, 2002). BIB Lembang menjaga hubungan yang telah terjalin dengan pelanggan dengan menggunakan layanan excellence service, yaitu layanan purna jual seperti konsultasi, pendampingan, serta kegiatan monitoring.

\section{Value Stream-Returns}

Arus nilai yang berada pada organisasi non profit merupakan nilai moneter yang berada pada organisasi tersebut, yaitu berupa pencapaian yang diperoleh dari jasa yang ditawarkan organisasi. BIB Lembang sendiri telah berhasil mencapai target yang diberikan pemerintah dalam proses produksi dan distribusi semen beku yang dijalankan. 


\section{Key Resources}

Key resources menggambarkan sumberdaya yang dimiliki oleh organisasi. Dalam hal ini BIB Lembang memiliki sumberdaya yang terdiri dari tangible Key resources, yaitu bangunan beserta seluruh peralatannya, serta intangible Key resources berupa sumberdaya manusia yang sudah terlatih.

\section{Key Activities}

Key Activities merupakan serangkaian kegiatan utama yang dilakukan berdasarkan fungsi dan tujuan dibentuk organisasi. Menurut Priyanto (2011) koordinasi antar institusi dari tingkat pusat sampai daerah dalam implementasi program di lapangan sangat penting. Koordinasi tersebut meliputi perencanaan dan implementasi program, keterkaitan dan tanggung jawab masing-masing institusi, serta pemantauan dan evaluasi secara periodik. Key Activities yang dilakukan oleh BIB Lembang saat ini antara lain 1) aktivitas pemeliharaan, 2) aktivitas kegiatan monitoring dan evaluasi, 3) aktivitas kegiatan BIMTEK (Bimbingan Teknis).

\section{Key Partnership}

Key Partnership merupakan mitra kerja BIB Lembang dalam menjalankan fungsi sebagai balai yang mendukung pemerintah dalam memenuhi pelaksanaan kegiatan inseminasi buatan. Mitra yang dimiliki oleh BIB Lembang antara lain Dinas Peternakan Provinsi, perguruan tinggi, balai penelitian, dan kelompok peternak.

\section{Value Stream-Outlay and Costs}

Value stream-outlay and costs merupakan biaya yang dibutuhkan untuk mengoperasikan organisasi dalam mewujudkan value proposition yang diberikan. Biaya yang dibutuhkan oeh BIB Lembang dalam menjalankan kegiatannya antara lain yaitu, 1) biaya belanja pegawai, 2) biaya belanja honorarium, 3) biaya belanja barang, 4) biaya belanja modal, 5) biaya belanja pemeliharaan, 6) biaya perjalanan, dan 7) biaya belanja jasa.

Penjabaran masing-masing elemen diatas kemudian diagambarkan kedalam sebuah kanvas dapat dilihat pada Gambar 2.

\begin{tabular}{|c|c|c|c|c|}
\hline \multirow[t]{2}{*}{$\begin{array}{l}\text { Key Partnerships } \\
\\
\text { - Dinas peternakan } \\
\text { - Perguruan tinggi } \\
\text { - Balai penelitian } \\
\text { - Kelompok peternak }\end{array}$} & $\begin{array}{l}\quad \text { Key Activities } \\
\\
\text { - Pemeliharaan ternak } \\
\text { - Monev } \\
\text { - Bimtek }\end{array}$ & \multirow{2}{*}{$\begin{array}{l}\text { Value Propositions } \\
\text { - Penyediaan } \\
\text { semen beku } \\
\text { unggul } \\
\text { - Asistensi dan } \\
\text { konsultasi } \\
\text { peternakan } \\
\text { - Pemanfaatan aset } \\
\text { balai }\end{array}$} & $\begin{array}{c}\text { Relations } \\
\text { - Personal assistance }\end{array}$ & \multirow{2}{*}{$\begin{array}{l}\text { Co-Creator } \\
\text { - Direktorat } \\
\text { pembibitan dan } \\
\text { produksi ternak } \\
\text { - Kelompok } \\
\text { peternak } \\
\text { - Perusahaan } \\
\text { swasta } \\
\text { - Masyarakat } \\
\text { umum }\end{array}$} \\
\hline & $\begin{array}{c}\text { Key Resources } \\
\text { - Tangible key resource } \\
\text { - Intengible key resource }\end{array}$ & & $\begin{array}{l}\text { Channels } \\
\\
\text { - Disribusi langsung } \\
\text { - Distribusi tidak } \\
\text { langsung }\end{array}$ & \\
\hline \multicolumn{2}{|c|}{ Value Stream Outlay and Cost } & \multicolumn{3}{|c|}{$\begin{array}{l}\text { - Tercapainya target produksi } \\
\text { - Tercapainya target distribusi } \\
\text { - Nilai PNBP diatas target } \\
\text { - ISO 17025: } 2005 \text { dan ISO 9001: } 2008\end{array}$} \\
\hline
\end{tabular}

Gambar 2. BMC BIB Lembang saat ini 


\section{Model Bisnis Perbaikan BMC BIB Lembang}

Setelah mengidentifikasi elemen BMC di BIB Lembang saat ini, maka tahap selanjutnya adalah melakukan analisis SWOT pada setiap elemen BMC saat ini. Hasil dari analisis SWOT ini dapat digunakan untuk menyempurnakan business model yang telah diterapkan sehingga organisasi dapat semakin berkembang. Melalui analisis ini dapat diketahui elemen mana yang dapat dioptimalkan, diperbaiki, ataupun dirubah untuk keberlangsungan organisasi di masa yang akan datang.

Hasil observasi, pengisian kuesioner, dan wawancara maka diperoleh hasil analisis SWOT dari masingmasing elemen BMC BIB Lembang adalah sebagai berikut:

\section{Co-Creator}

Kekuatan (strength) dari Co-Creator BIB Lembang adalah pelanggan yang loyal. Kelemahan (weakness) dari Co-Creator BIB Lembang adalah informasi yang diberikan belum merata. Peluang (opportunities) dari Co-Creator BIB Lembang adalah pemerintah sadar akan pentingnya inseminasi buatan. Ancaman (threats) dari Co-Creator BIB Lembang adalah peternak daerah tertentu tidak dapat memakai semen dari luar daerah.

\section{Value Proposition}

Kekuatan (strength) dari Value Proposition BIB Lembang adalah semen beku kualitas unggul. Kelemahan (weakness) dari Value Proposition BIB Lembang adalah keterbatasan jumlah jenis semen beku. Peluang (opportunities) dari Value Proposition BIB Lembang adalah peternak yang mulai sadar akan manfaat inseminasi buatan. Ancaman (threats) dari Value Proposition BIB Lembang adalah harga semen di pesaing yang lebih murah.

\section{Channels}

Kekuatan (strength) dari Channels BIB Lembang adalah sistem E-Katalog yang dimiliki BIB Lembang. Kelemahan (weakness) dari Channels BIB Lembang adalah terbatasnya akses E-Katalog kepada pihak tertentu. Peluang (opportunities) dari Channels BIB Lembang adalah perkembangan teknologi yang semakin pesat. Ancaman (threats) dari Channels BIB Lembang adalah kemampuan pemanfaatan teknologi yang belum merata di semua daerah.

\section{Relations}

Kekuatan (strength) dari Relations BIB Lembang adalah komunikasi rutin yang dilakukan melalui personal assistance. Kelemahan (weakness) dari Relations BIB Lembang adalah terbatasnya jumlah SDM personal assistance. Peluang (opportunities) dari Relations BIB Lembang adalah penggunaan jejaring sosial yang optimal. Ancaman (threats) dari Relations BIB Lembang adalah pesaing BIB Lembang yang semakin gencar melakukan promosi terhadap pelanggan.

\section{Value Stream-Return}

Kekuatan (strength) dari Value Stream-Return BIB Lembang adalah capaian BIB Lembang yang selalu memenuhi target. Kelemahan (weakness) dari Value Stream-Return BIB Lembang adalah hasil pendapatan dari capaian tidak dapat diakses. Peluang (opportunities) dari Value Stream-Return BIBLembang adalah perubahan sistem pengelolaan keuangan Badan Layanan Umum (BLU). Ancaman (threats) dari Value Stream-Return BIB Lembang adalah terjadinya keterlambatan pencairan dana dari pemerintah.

\section{Key Resources}

Kekuatan (strength) dari Key Resources BIB Lembang saat ini adalah BIB Lembang mempunya sumberdaya yang mendukung. Kelemahan (weakness) dari Key Resources BIB Lembang adalah sapi mulai memasuki usia yang tidak produktif. Peluang (opportunities) dari Key Resources BIB Lembang adalah BIB Lembang dapat melakukan kerja sama dengan lembaga penelitian atau swasta untuk melahirkan produk baru. Ancaman (threats) dari Key Resources BIB Lembang adalah desakan masyarakat sekitar terkait aktivitas yang dilakukan dikarenakan BIB Lembang memiliki lokasi di tengah pemukiman penduduk.

\section{Key Activities}

Kekuatan (strength) dari Key Activities BIB Lembang saat ini adalah kegiatan monitoring dan evaluasi yang dilakukan secara rutin. Kelemahan (weakness) dari Key Activities BIB Lembang adalah terkadang anggaran tidak sesuai sehingga aktivitas yang akan dilakukan tidak berjalan. Peluang (opportunities) dari Key Activities BIB Lembang adalah masih terdapat banyak daerah yang belum mengenal teknologi insemniasi buatan, sehingga BIB Lembang dapat memperluas 
aktivitas ke daerah introduksi, atau daerah pengenalan yang belum mengetahui manfaat inseminasi buatan. Ancaman (threats) dari Key Activities BIB Lembang adalah masih terdapatnya peternak tradisional sehingga belum mau memakai inseminasi buatan.

\section{Key Partnership}

Kekuatan (strength) dari Key Partnership BIB Lembang adalah memiliki mitra yang banyak hampir di semua daerah. Kelemahan (weakness) dari Key Partnership BIB Lembang adalah karena banyaknya mitra yang dimiliki, terkadang permintaan mitra tidak dapat terpenuhi oleh BIB Lembang. Peluang (opportunities) dari Key Partnership BIB Lembang adalah BIB Lembang dapat melibatkan mitra untuk melakukan penyuluhan terkait pengembangan inseminasi buata kepada peternak di daerah masing-masing. Ancaman (threats) dari Key Partnership BIB Lembang adalah terdapatnya kelembagaan mitra yang kurang teratur sehingga dapat menyebabkan permasalahan bagi BIB Lembang.

\section{Value Stream-Outlay and Costs}

Kekuatan (strength) dari Value Stream Outlay and Costs BIB Lembang adalah alokasi anggaran yang dilakukan sudah cukup baik. Kelemahan (weakness) dari Value Stream Outlay and Costs BIB Lembang adalah penyusunan Rencana Kerja dan AnggaranKementrian dan Lembaga (RKAKL) belum disusun berdasarkan kebutuhan real, sehingga alokasi dana tidak optimal. Peluang (opportunities) dari Value Stream Outlay and Costs BIB Lembang adalah pemerintah mulai sadar akan pentingnya inseminasi buatan, sehingga dana pengembangan untuk IB menjadi prioritas. Ancaman (threats) dari Value Stream Outlay and Costs BIB Lembang adalah penyusunan anggaran terkadang berdasarkan data yang tidak valid sehingga dapat menjadi ancaman bagi anggaran kegiatan di BIB Lembang.

\section{Perbaikan BMC BIB Lembang}

Upaya pengembangan organisasi dapat dilakukan dengan melakukan beberapa perubahan. Organisasi perlu mengetahui faktor-faktor apa saja yang dapat mendorong organisasi untuk melakukan perubahan. Kondisi tersebut memaksa para pihak untuk mengembangkan aset-aset yang dimilikinya untuk dapat bertahan menghadapi setiap perubahan yang akan terjadi (Purhantara, 2009). Desain model bisnis organisasi yang baru harus dapat merangsang lintas fungsional dan kolaborasi lintas organisasi, mampu mengurangi hambatan di lingkungan model bisnis serta mampu menyelaraskan bisnis dengan lingkungan internal dan eksternal yang terus berubah (Carayannis, 2014).

Perbaikan business model canvas di BIB Lembang dilakukan dengan bantuan analisis SWOT di setiap elemen bisnis model. Melalui analisis SWOT tersebut akan ditemukan apa saja yang menjadi prospek bagi organisasiyangharusdipertahankan sertadikembangkan dan juga kendala-kendala yang dihadapi oleh organisasi dan bagaimana solusi untuk memperbaiknya.

\section{Perbaikan elemen Co-Creator}

Upaya perbaikan yang dapat dilakukan yaitu memberikan pemerataan dan kemudahan akses informasi yang efektif seperti melakukan penyuluhan di setiap dinas peternakan daerah agar informasi yang disampaikan dapat diterima dengan baik sekaligus memberi penjelasan terhadap co-creator yang dimiliki oleh BIB Lembang terkait dengan program yang dilaksanakan oleh pemerintah untuk pengembangan inseminasi buatan di Indonesia.

\section{Perbaikan elemen Value Proposition}

Upaya perbaikan yang dapat dilakukan, yaitu BIB Lembang dapat melakukan analisis permintaan terhadap produk yang ditawarkan sehingga BIB Lembang dapat memproduksi lebih banyak pada produk yang lebih diminati oleh pelanggan.

\section{Perbaikan elemen Channels}

Upaya perbaikan yang dapat dilakukan yaitu memberikan akses E-Katalog terhadap kalangan umum agar penyampaian informasi nilai yang ditawarkan BIB Lembang semakin tersebar luas.

\section{Perbaikan elemen Relations}

Upaya perbaikan yang dapat dilakukan yaitu menambah sumber daya manusia pada bagian personal assistance sehingga pelanggan yang dapat dilayani dalam waktu bersamaan dapat bertambah, dan meningkatkan tingkat kepuasan pelanggan terhadap BIB Lembang. 
Upaya perbaikan yang dapat dilakukan yaitu dengan menerapkan sistem Badan Layanan Umum (BLU) pada BIB Lembang sehingga pengalokasian hasil dapat lebih optimal.

\section{Perbaikan eleman Key Resources}

Upaya perbaikan yang dapat dilakukan, yaitu mengganti sapi yang sudah kurang produktif dengan sapi baru yang lebih produktif, atau melakukan kegiatan tambahan berupa excercise yang dilakukan terhadap sapi kurang produktif, agar produksi semennya dapat menjadi lebih optimal.

\section{Perbaikan elemen Key Activities}

Upaya perbaikan yang dapat dilakukan, yaitu melakukan perencanaan alokasi anggaran secara tepat serta mengundang para peternak untuk melaksanakan pelatihan persuasif secara terpusat dan menunjukkan contoh keberhasilan yang didapat melalui inseminasi buatan bagi peternakan sehingga alokasi dana yang digunakan untuk kegiatan monitoring dan evaluasi dapat lebih efisien.

\section{Perbaikan elemen Key Partnership}

Upaya perbaikan yang dapat dilakukan yaitu melakukan koordinasi secara teratur dengan mitra terkait penyuluhan yang dilakukan serta analisis permintaan semen beku agar BIB Lembang senantiasa dapat memenuhi permintaan produk yang diinginkan oleh mitra.

\section{Perbaikan elemen Value Stream-Outlay and Costs}

Upaya perbaikan yang dapat dilakukan yaitu melakukan optimalisasi perencanaan alokasi anggaran secara tepat dan real sesuai kebutuhan sebelum menuangkan ke dalam RKAKL. Sehingga alokasi anggaran untuk suatu kegiatan dapat tersampaikan serta serapan anggaran BIB Lembang menjadi lebih optimal.

Perbaikan yang dilakukan terhadap masing-masing elemen akan digunakan sebagai dasar untuk menentukan program perbaikan yang akan digunakan sebagai strategi pengembangan bagi BIB Lembang, dapat dilihat pada Gambar 3.

\begin{tabular}{|c|c|c|c|c|c|}
\hline \multirow{3}{*}{$\begin{array}{l}\text { Key Partnerships } \\
\text { - Dinas peternakan } \\
\text { - Perguruan tinggi } \\
\text { - Balai penelitian } \\
\text { - Kelompok peternak } \\
\text { - Koordinator teratur } \\
\text { dengan mitra terkait } \\
\text { penyuluhan }\end{array}$} & \multirow{2}{*}{$\begin{array}{l}\quad \text { Key Activities } \\
\text { - Pemeliharaan ternak } \\
\text { - Monev } \\
\text { - Bimtek } \\
\text { - } \frac{\text { Melaksanakan }}{\text { pelatihan persuasif }}\end{array}$} & \multirow{3}{*}{\multicolumn{2}{|c|}{$\begin{array}{l}\text { Value Propositions } \\
\text { - Penyediaan } \\
\text { semen beku } \\
\text { unggul } \\
\text { - Asistensi dan } \\
\text { konsultasi } \\
\text { peternakan } \\
\text { - Pemanfaatan aset } \\
\text { balai } \\
\text { - Melakukan } \\
\text { analisis } \\
\text { permintaan } \\
\text { pelanggan }\end{array}$}} & \multirow{2}{*}{$\begin{array}{l}\quad \text { Relations } \\
\text { - Personal assistance } \\
\text { - Menambah } \\
\frac{\text { Sumberdaya untuk }}{\text { melakukan fungsi }} \\
\text { personal assistance }\end{array}$} & \multirow{3}{*}{\begin{tabular}{|l}
\multicolumn{1}{|c}{ Co-Creator } \\
- Direktorat \\
pembibitan dan \\
produksi ternak \\
- Kelompok \\
peternak \\
- Perusahaan \\
swasta \\
- Masyarakat \\
umum \\
- Pemerataan \\
serta \\
kemudahan \\
akses informasi \\
kepada co- \\
creator
\end{tabular}} \\
\hline & & & & & \\
\hline & 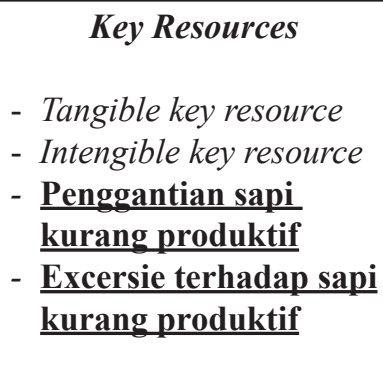 & & & $\begin{array}{l}\text { - Disribusi langsung } \\
\text { - Distribusi tidak } \\
\text { langsung } \\
\text { - Pemberian akses } \\
\text { E-katalog terhadap } \\
\text { pihak non dinas }\end{array}$ & \\
\hline \multicolumn{3}{|c|}{$\begin{array}{l}\text { - Belanja pegawai dan honorarium } \\
\text { - Belanja barang, modal dan jasa } \\
\text { - Pemeliharaan dan perjalanan } \\
\text { - Melakukan optimalisasi perencanaan alokasi anggaran } \\
\text { secara tepat dan real }\end{array}$} & \multicolumn{3}{|c|}{$\begin{array}{l}\text { - Tercapainya target produksi } \\
\text { - Tercapainya target distribusi } \\
\text { - Nilai PNBP diatas target } \\
\text { - ISO 17025: 2005 dan ISO 9001: } 2008 \\
\text { - Penerapan sistem BLU }\end{array}$} \\
\hline
\end{tabular}

Gambar 3. Business Model Canvas BIB Lembang yang telah diperbaiki 


\section{Program Perbaikan Business Model Canvas BIB Lembang}

Hasil business model yang telah diperbaiki, berikut merupakan program perbaikan yang dapat menjadi pertimbangan BIB Lembang sebagai strategi pengembangan terkait perbaikan business model canvas yang telah dilakukan:

\section{Pengembangan internal organisasi BIB Lembang}

Salah satu upaya dalam pengembangan internal organisasi adalah melalui penataan kelembagaan dengan pembenahan internal organisasi. Pembenahan internal dapat dilakukan dengan melakukan program internal development berupa pelatihan, motivasi, dan evaluasi secara periodik bukan hanya terhadap pegawai internal BIB Lembang. Namun, juga melakukan koordinasi kepada mitra distribusi dari dinas peternakan. Pembenahan internal tersebut juga termasuk kepada pembenahan kualitas bahan baku untuk pembuatan produk. Pengadaan bibit baru sebagai regenerasi dari pejantan yang sudah tidak produktif harus dilakukan untuk mendukung keberlangsungan kegiatan yang ada di BIB Lembang.

2. Pengembangan saluran distribusi, informasi, dan sistem komunikasi terhadap peternak.

Potensi saluran distribusi dan informasi dapat memberikan keuntungan dan manfaat yang besar jika dikelola dengan baik. Pengelolaan yang baik dapat dilakukan jika memiliki SDM yang berkompetensi, khususnya dalam bidang berbasis ilmu dan teknologi. SDM yang berkompeten memiliki proporsi yang lebih besar dari nilai-nilai organisasi (Nielsen dan Montemari, 2012). Pihak organisasi dan pemerintah harus dapat berkolaborasi menyiapkan SDM yang profesional terkait manajemen pengelolaan informasi yang berada di BIB Lembang. Disamping itu, pengembangan sarana komunikasi E-Katalog dapat dilakukan agar dapat diakses oleh masyarakat umum, antara lain dengan menyertakan keunggulan produk, tata cara pemesanan, kontak dan alamat distributor resmi (dinas peternakan), serta jadwal bimbingan atau pelatihan yang akan dilakukan beserta kontak untuk pertanyaan atau permohonan pelatihan. Pelatihan, bimbingan, dan evaluasi dapat dilakukan secara periodik bersama-sama dengan dinas peternakan setempat. Dengan demikian, mempermudah pemantauan yang dilakukan oleh organisasi dalam hal penyampaian informasi.
3. Pengembangan pelayanan dan pendapatan negara berbasis pengelolaan keuangan Badan Layanan Umum (BLU).

Pihak organisasi maupun pemerintah terkait harus berani melakukan evolusi organisaisi dan pembenahan dalam pengelolaan BIB Lembang dengan cara merubah sistem organisasi sehingga mampu menggali nilai tambah bagi organisasi. Salah satunya adalah merubah sistem perngelolaan organisasi yang ada menjadi sistem pengelolaan keuangan BLU. Dua hal yang menjadi filosofi penetapan satuan kerja (satker) pemerintah dalam menerapkan pengelolaan keuangan BLU. Pertama, untuk meningkatkan pelayanan kepada masyarakat. Banyak pihak beranggapan bahwa pelayanan yang dilakukan oleh pemerintah kepada masyarakat belum berjalan dengan baik. serta filosofi yang kedua adalah dalam rangka membenahi pengelolaan PNBP (Santi dan Rosita, 2009).

Badan Layanan Umum (BLU) menganut pola pengelolaan anggaran fleksibilitas (flexible budget). Pola anggaran ini mengizinkan pemimpin BLU melakukan belanja lebih besar daripada yang ditetapkan dalam dokumen pelaksaanan anggaran. Dengan mengadaptasi sistem BLU alokasi anggaran dapat dikelola langsung oleh BIB lembang. Sehingga dapat meminimalisir alokasi anggaran yang tidak tepat sasaran. Disisi lain perubahan organisasi dalam mengadaptasi sitem pengelolaan BLU harusalah sangat matang dan memerlukan perencanaan yang terstruktur. Sehingga perubahan sistem organisasi tidak menjadi ancaman dan menimbulkan permasalahan terhadap sistem yang sudah ada.

\section{Implikasi Manajerial}

Langkah awal yang dapat dilakukan oleh BIB Lembang dalam rangka pengembangan organisasi adalah dengan melakukan pembenahan internal yang berada dalam organisasi itu sendiri, hal tersebut dapat dilakukan dengan meningkatkan kualitas sumberdaya, baik sumber daya fisik, maupun SDM yang ada di BIB Lembang. Selain pembenahan internal, diperlukan adanya hubungan yang baik dengan seluruh mitra agar saluran distiribusi, baik informasi maupun komunikasi dapat berkembang sehingga nilai yang ditawarkan organisasi dapat tersampaikan secara merata ke seluruh pihak yang terkait dengan pengembangan peternakan di Indonesia. Disisi lain perubahan sistem pengelolaan keuangan BIB Lembang dapat dirubah 
menjadi pola pengelolaan BLU sehingga pengelolaan sumberdaya dapat lebih efektif dan efisien. Seluruh perbaikan dan perubahan yang ada di BIB Lembang bertujuan agar BIB Lembang dapat lebih berkembang dalam menjalankan fungsinya sebagai jasa pelayanan penyedia semen beku unggul dalam rangka pemenuhan kebutuhan penlaksanaan inseminasi buatan yang ada di Indonesia.

\section{KESIMPULAN DAN SARAN}

\section{Kesimpulan}

Identifikasi model bisnis BIB Lembang saat ini terdiri dari sembilan elemen, yaitu Co-Creator, Value Proposition, Channels, Relations, Value Stream-Return, Key Resources, Key Activities, Key Partership, dan Value Stream-Outlay and Costs. Hasil dari model bisnis yang telah disempurnakan menunjukkan terjadi perbaikan di masing-masing elemen yang terdiri dari pemerataan dan kemudahan informasi, melakukan analisis permintaan pelanggan, pemberian akses E-Katalog terhadap pihak non-dinas, penambahan SDM personal assistance, penerapan sistem BLU, penggantian sumberdaya tidak produktif, pelatihan persuasif terhadap peternak, melakukan koordinasi dengan mitra terkait penyuluhan, dan optimalisasi perencanaan alokasi anggaran. Program perbaikan yang dapat dilakukan antara lain, pengembangan Balai pengembangan Balai Inseminasi Buatan Lembang terdiri dari pengembangan internal organisasi BIB Lembang, pengembangan saluran distribusi, informasi, dan sistem komunikasi terhadap peternak, serta pengembangan optimalisasi pelayanan dan pendapatan negara berbasis pengelolaan keuangan BLU.

\section{Saran}

Saranyang dapat diberikan kepada pihak BIB Lembang terkait upaya pengembangan Balai Inseminasi Buatan Lembang adalah sebagai berikut: Pihak organisasi BIB Lembang perlu melihat aspek internal dan eksternal dalam melakukan pengembangan organisasi. Perbaikan aspek internal sebaiknya lebih dahulu dilakukan, sebelum memasuki aspek eksternal. Perbaikan yang dapat dilakukan yaitu dengan pembenahan sektor internal organisasi serta koordinasi yang teratur dengan pihak luar demi keberlangsungan aktivitas yang dilakukan oleh BIB Lembang.
Pembaharuan sumber daya berupa sapi yang sudah memasuki masa tidak produktif merupakan faktor penting dalam keberlangsungan kegiatan yang ada di BIB Lembang. Dengan sumberdaya yang tidak mendukung maka tujuan pengembangan BIB Lembang dapat terhambat dan tujuan utama organisasi dalam pemenuhan kebutuhan pelaksanaan inseminasi buatan di Indonesia tidak tercapai. Implementasi dari program perbaikan dan business model yang telah diperbaiki dalam penelitian ini dapat digunakan oleh BIB Lembang untuk memberikan gambaran kerja organisasi secara menyeluruh sehingga mempermudah memperbaiki atau merubah aspek-aspek yang dinilai kurang tepat.

\section{DAFTAR PUSTAKA}

Apavaloaie EI. 2014. The impact of the internet on the business environment. Procedia Economics and finance 15: 951-958. https://doi.org/10.1016/ S2212-5671(14)00654-6

Becker J, Algermissen L, Niehaves B. 2006. A procedure model for process oriented e-goverment projects. Business Process Management Journal 1(12): 61-75. https://doi. org/10.1108/14637150610643760

Carayannis EG, Sindakis S, Walter C. 2014. Business model innovation as level of organizational sustainability. Journal of Technology Transformation 40: 85-104. https://doi. org/10.1007/s10961-013-9330-y

Darmawati A. 2007. Mengelola suatu perubahan dalam organisasi. Jurnal Ilmu Manajemen 3(1): $51-58$.

Dudin MN, Lyasnikov NV, Leont'eva LS, Reshetov KJ, Sidorenko VN. 2015. Business model canvas as a basis for the competitive advantage of enterprise structures in the industrial agriculture. Biosci, Biotech, Res Asia 12(1): 887-894. https://doi. org/10.13005/bbra/1736

Graves T. 2011. Using Business Model Canvas for NonProfit. http://weblog.tetradian.com/2011/07/16/ bmcanvas-for-nonprofits/ [10 Maret 2017].

Lasker RD, Weiss ES. 2003. Creating Partnership: The critical role of community stakeholder. Journal of Health and Human Services Administration 26(1/2): 132-133.

Mardiyanto A. 2002. Studi mengenai kreatifitas program dan kinerja pemasaran. Jurnal of Business Manegement 1(1): 57-58. 
Morris L. 2013. Business model warfare: The strategy of business breakthroughs. Journal of Business Models 1(1): 13-37.

Nielsen C, Montemari M. 2012. The role of human resource in business model performance: the case of network-based companies. Journal of Human Resource CostingandAccounting 16(2):142-164. https://doi.org/10.1108/14013381211284254

Prahalad CK, Ramaswamy V. 2004. Co-creation experiences: the next practice in value creation. Journal of Interactive Marketing 18(3):5-14. https://doi.org/10.1002/dir.20015

Priyanto D. Strategi pengembangan usaha ternak sapi potong dalam mendukung program swasembada daging sapi dan kerbau tahun 2014. Jurnal Litbang Pertanian 30(3): 108-116.

Purhantara W. 2009. Organizational development based change management. Jurnal Ekonomi dan Pendidikan 6(2): 154-166.

Qastharin AR. 2016. Business model canvas for social enterprise. Journal of Business and Economiscs 7(4): 627-637.
Romjali, Mariyono, Wijono dan Haryati. 2007. Rakitan Teknologi Pembibitan Sapi Potong. Loka Penelitian Sapi Potong Grati PasuruanJawa Timur. Bogor: Pusat Penelitian dan Pengembangan Peternakan.

Santi E, Rosita I. 2009. lmplementasi dan kendala penerapan pengelolaan keuangan badan layanan umum (BLU). Jurnal Akuntansi dan Manajemen 4(2): 41-54.

Shafer SM, Smith HJ, Linder JC. 2005. The power of business models. Business Horizons 48(3):199-207.https://doi.org/10.1016/j. bushor.2004.10.014

Sinfield JE, Calder B, Mcconnel, dan S Colson. 2012. How to identify new business models: systematical exploring alternative approaches to value creation can allow companies to find new oppurtunities for growth. Journal of MIT Sloan Management Review 53(2): 85-89.

Umar H. 2010. Desain Penelitian Manajemen Strategik: Cara Mudah Meneliti Masalah-Masalah Manajemen Strategik untuk Skripsi, Thesis, dan Praktik Bisnis. Jakarta: Rajawali Pers. 